\title{
1 A MODIS-Based Automated Flood Monitoring System for \\ 2 Southeast Asia
}

4 A. Ahamed ${ }^{1,2}$, J.D. Bolten ${ }^{2}$

5 [1]\{USRA GESTAR, 7178 Columbia Gateway Drive, Columbia, MD 21046\}

6 [2]\{NASA Goddard Space Flight Center, 8800 Greenbelt Road, Greenbelt, MD, 20771 \}

7 Correspondence to: Aakash Ahamed (aakashahamed@gmail.com; aakash.ahamed@nasa.gov; 8 john.bolten@nasa.gov)

9

\section{Abstract}

Flood disasters in Southeast Asia result in significant loss of life and economic damage. Remote sensing information systems designed to spatially and temporally monitor floods can help governments and international agencies formulate effective disaster response strategies during a flood and ultimately alleviate impacts to population, infrastructure, and agriculture. Recent destructive flood events in the Lower Mekong River Basin occurred in 2000, 2011, 2013, and 2016 (http://ffw.mrcmekong.org/historical_rec.htm, April 24, 2017).

The large spatial distribution of flooded areas and lack of proper gauge data in the region makes accurate monitoring and assessment of impacts of floods difficult. Here, we discuss the utility of applying satellite-based Earth observations for improving flood inundation monitoring over the flood-prone Lower Mekong River Basin. We present a methodology for determining near real-time surface water extent associated with current and historic flood events by training surface water classifiers from 8-day, 250-meter Moderate-resolution Imaging Spectroradiometer (MODIS) data spanning the length of the MODIS satellite record. The Normalized Difference Vegetation Index (NDVI) signature of permanent water bodies (MOD44W; Carroll et al., 2009) is used to train surface water classifiers which are applied to a time period of interest. From this, an operational nowcast flood detection component is produced using twice daily imagery acquired at 3-hour latency which performs image compositing routines to minimize cloud cover. Case studies and accuracy assessments against radar-based observations for historic flood events are presented. The customizable system has 
1 been transferred to regional organizations and near real-time derived surface water products are made available through a web interface platform. Results highlight the potential of near real-time observation and impact assessment systems to serve as effective decision support tools for governments, international agencies, and disaster responders.

\section{Keywords:}

Remote Sensing, Image Classification, Flooding, Disasters, Natural Hazards, MODIS

\section{Introduction}

Southeast Asia is one of the most flood prone regions in the world. Floods have been

11 particularly frequent and costly in the developing countries of Southeast Asia where large 12 portions of the population live on or near the floodplain (Jonkman, 2005; Kirsch et al., 2012; 13 Long and Trong, 2001; Stromberg, 2007). Regional studies (Knox, 1993; Mirza, 2002; 14 Schiermeier, 2011; Västilä et al, 2010) and Intergovernmental Panel on Climate Change (IPCC, 2007) projections suggest that precipitation extremes and flood frequency are increasing. During a typical monsoon, the surface water extent of Tonle Sap Lake in Cambodia increases by some 500\% (Figure 1; MRC, 2005). At low stages during the dry season, Tonle Sap Lake may contain water volumes of $1-2 \mathrm{~km}^{3}$ while at the end of the wet season it may contain 50-80 $\mathrm{km}^{3}$ (MRC, 2005). The region has experienced sea level rise and intensified flood and drought in the last $30-50$ years (IPCC, 2014). Recent destructive flood events in the Lower Mekong River Basin occurred in 2000, 2011, 2013, and 2016, causing widespread loss of life, significantly damaged infrastructure and jeopardized economic April 24, 2017 , http://reliefweb.int/sites/reliefweb.int/files/resources/Cambodia\%20Final\%20report_07dec20 13.pdf, April 24, 2017). Thus, there is a need for rapid automated and customizable systems to monitor flooding in these vulnerable areas.

Organizations like the Mekong River Commission (MRC) and the Asian Disaster Preparedness Center (ADPC) are establishing regional flood forecasting systems by synergistically combining gauge data and hydrologic models (MRC, 2011). While valuable for rapid response, these efforts are inhibited by sparse coverage of rain and stream gage stations, which are used to force and calibrate hydrologic models. Furthermore, a complex 
1 regional hydrodynamic system featuring widespread dikes, diversions, irrigation channels,

2 dams, reservoirs and low gradient deltaic terrain makes hydrologic modeling a challenging 3 task.

4 In situ observations are a key component to calibration and validation of flood forecast models. However, determining flood extent from in situ observations and on-the-ground efforts is expensive, impractical, and can be inaccurate (Brakenridge and Anderson, 2006). Space-borne and airborne visible and near infrared imagery can provide consistent, rapid, and repeat measurements of flooding through time over large geographic areas (Kussul et al., 2011; Kuenzer et al., 2013; Huang et al., 2014). Several efforts undertaken to date have aimed to provide enhanced information about floods in near real-time using remotely sensed satellite data (e.g. Brakenridge and Anderson, 2006; Martinis et al., 2013; Wu et al., 2014). However, these platforms present derived products, and each approach are subject to various limitations (Section 2). The system described here leverages several techniques used in these studies (e.g., time-series analysis, MODIS-based flood detection, etc.,). We aim to compliment this previous work by implementing near real-time MODIS-based observations, a cloud filtering routine, and image compositing and classification framework provided on an operational webbased mapping platform. To this end, we demonstrate the feasibility of an operational near real-time MODIS-based system for monitoring flood extent. It is noted that other sensors (e.g., radar, microwave) may be better for mapping flooded areas, however, our aim was to use widely available and free data in a straightforward approach that can be easily applied, adapted, and implemented by regional stakeholders. We test this simple method to classify surface water based on classifiers trained from MODIS NDVI climatologies, and extend this framework to a near real-time system to monitor flood extent, which has successfully detected floods and is being transferred to regional partners for incorporation with existing tools.

A python software framework was developed to determine surface water extent at $250 \mathrm{~m}$ resolution for historic, ongoing, and future floods in a Southeast Asia study domain, defined here as $\left(97^{\circ} 16^{\prime} 36.09^{\prime \prime} \mathrm{E}, 23^{\circ} 25^{\prime} 32.03^{\prime \prime N}\right.$; 103ํำ $\left.34.94^{\prime \prime} \mathrm{E}, 14^{\circ} 30^{\prime} 0.66^{\prime \prime} \mathrm{N}\right)$. Algorithms were calibrated and validated using historic data, while supporting software was configured to continuously ingest the latest MODIS imagery to nowcast a sudden onset event. Web based interactive surface water maps and statistical impact plots (e.g. country level landcover 31 impacts) are updated daily and intended to serve as decision support tools for regional governments, international agencies, and the broader emergency response community. 


\section{Background and Previous Work}

3 Numerous studies and operational systems have used satellite data sources to determine

4 surface water extent for ongoing flood events, to forward model surface water extent due to rainfall, and to create inundation frequency maps from historical data.

\subsection{Methods to Determine Flood Extent from Satellite}

Optical imagery, radar and microwave sensors, and land-surface models have all been successfully employed to estimate surface water extent (Brakenridge and Anderson, 2006, Martinis et al., 2009, Martinis et al., 2013; Wu et al., 2014; Pekel et al., 2014). The daily repeat time and relatively high resolution $(250 \mathrm{~m})$ of MODIS instruments aboard Aqua and Terra makes it an attractive sensor for nowcast studies. Persistent cloud cover is nonetheless a significant obstacle for optical sensors like MODIS and Landsat, especially in tropical areas (Leinenkeugel et al., 2013). To maximize the utility of optical sensors, temporal image compositing, as described in Section 2, can increase spatial coverage of cloud-free observations (e.g. Chen et al., 2013; Leinenkeugel et al., 2013; Nigro et al., 2014).

Land-surface and hydrologic models work regardless of atmospheric conditions, and can estimate inundation depth, but resolution is often on the scale of $5 \mathrm{~km} \times 5 \mathrm{~km}$ or greater due to sparse model parameter and forcing data (Lauri et al., 2012). Downscaled hydrologic models can operate at $\sim 1 \mathrm{~km}$ resolution (e.g. Schumann et al., 2013) but are limited by coarse meteorological data and potentially large uncertainties (Voisin et al., 2008)

Microwave radar is an attractive option for monitoring surface water extent. Microwave radar penetrates clouds, is sensitive to water, and data is attainable at medium-high resolution (e.g., $5 \mathrm{~m}-25 \mathrm{~m}$ ), rendering these systems extremely useful for flood detection (Long and Trong, 2001; Kussul et al., 2011; Kuenzer et al., 2013; Westerhoff et al., 2013; Schlaffer et al., 2017). However, orbiting radar satellites have a narrow swath and longer repeat cycles (e.g. Sentinel-1 repeat cycle of 12 days), while other radar satellites must be tasked for data acquisition (e.g. ENVISAT Advanced Synthetic Aperture Radar, and TerraSAR-X). For these reasons, acquiring complete coverage of an area is prohibitively time-consuming and is not easily implemented for rapid deployment and assessment. Thus, continuous now-casting and 
1 near real-time flood monitoring by any satellite is a challenging task for Southeast Asia and

2 all flood prone regions. Kuenzer et al (2015) demonstrated the utility of spatially coarse but

3 temporally dense MODIS data for mapping flood inundation over several basins, including

4 the Mekong.

\section{$5 \quad 2.2$ Near real-time Flood Monitoring Systems}

6 Visible, Near Infrared (NIR), and microwave observations are regularly employed for near7 real time mapping of floods. The Dartmouth Flood Observatory (DFO; 8 http://floodobservatory.colorado.edu/) and Near Real-time Global Flood Mapping Project 9 (http://oas.gsfc.nasa.gov/floodmap/index.html) use an algorithm applied to near real-time MODIS imagery (Bands 1,2, and 6) to detect surface water at $500 \mathrm{~m}$ resolution (Brakenridge and Anderson, 2006). The Flood Observatory web site (http://floodobservatory.colorado.edu/) provides recent and historical archives of global flooding detected with the algorithm, as well as other flood information such as discharge estimates. Accuracy assessment of this product on a global scale is still ongoing (Nigro et al., 2014).

The Global Flood Monitoring System (http://flood.umd.edu) uses downscaled near real-time radar precipitation data $(12 \mathrm{~km}$ resolution) from the Global Precipitation Measurement Mission (GPM) coupled with a modified Variable Infiltration Capacity (VIC) hydrologic land surface model to produce a global flood product that updates every three hours (Wu et al., 2014). These products are not limited by cloud cover but are inhibited by relatively coarse inputs.

The United Nations Institute for Training and Research (UNITAR) supports satellite data collection of natural disasters through the Operational Satellite Applications Programme (UNOSAT). UNOSAT radar satellites (e.g. Radarsat 2, ENVISAT Advanced Synthetic Aperture Radar [SAR], TerraSAR-X, Disaster Monitoring Constellation [DMC]) can be tasked to image areas following a flood or other hazardous event.

\subsection{Inundation Frequency}

The changing distribution of surface water has impacts for climate, biodiversity, economy, and human wellbeing (Huang et al., 2014; Pekel et al., 2016). Numerous recent studies (e.g.

30 Donchyts et al., 2016; Klein et al., 2015; Pekel et al., 2014) highlight the capability of optical 
1 remote sensing to better quantify temporal inundation dynamics in major rivers, coastal

2 wetlands, and large river deltas around the world, where water extent exhibits high temporal

3 variability. Kuenzer et al., (2015) highlight the need for high temporal frequency maps in

4 densely populated areas like the Mekong; Klein et al., 2015 illustrate the successful

5 application of dynamic thresholding MODIS imagery to produce high frequency surface

6 water maps. Using the Murray-Darling basin in Australia as a case study, Huang et al. (2014)

7 illustrate that surface water detection algorithms applied to MODIS imagery can be effective

8 at the basin scale, and point out the utility of combining in situ gage measurements, models,

9 and remote sensing observations to better manage regional water resources.

10 Landsat-based surface water frequency analyses (e.g. Donchyts et al., 2016; Pekel et al., 11 2016) have the advantage of higher resolution sensors (30m) and a long record (1970's 12 present), but lack the twice-daily temporal frequency of MODIS, making them useful for risk 13 mapping and determining trends, but less useful in rapid response, disaster monitoring 14 scenarios.

\section{Methodology}

\section{$17 \quad 3.1$ Study Area - Lower Mekong River Basin}

18 The Lower Mekong River Basin (LMB) is home to 65 million inhabitants residing in

19 Thailand, Vietnam, Cambodia, and Laos (MRC, 2010; Figure 1). 


\section{Study Area: Southeast Asia}

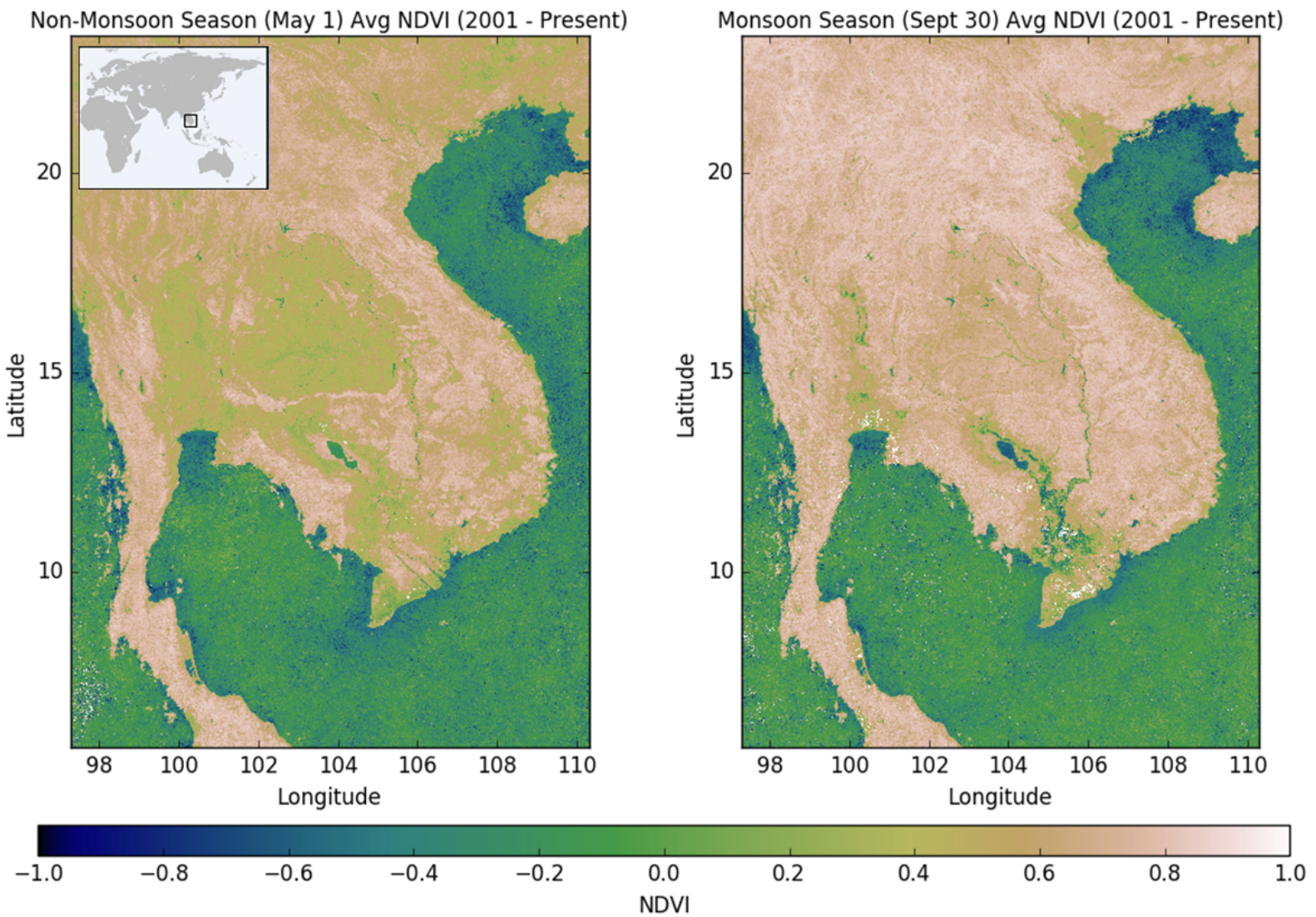

2 Figure 1: Study Area in Southeast Asia. The left image depicts NDVI climatology (2000 3 2015) for May $1^{\text {st }}$ from and right image shows average NDVI climatology $(2000-2015)$ for

4 September $30^{\text {th }}$. Strong regional seasonality is illustrated by differences in NDVI, particularly 5 around the Tonle Sap and Mekong Delta region (near $13^{\circ} \mathrm{N}, 104^{\circ} \mathrm{W}$ ). Persistent cloud cover is

6 shown in white. Decreases in NDVI shown in the right-hand image indicate annual flooding 7 due to monsoon rainfall.

9 The Mekong River is the $12^{\text {th }}$ longest river in the world, has the $8^{\text {th }}$ largest discharge, and 10 contains the most biodiverse ecosystems of any other river system, with the exception of the 11 Amazon (MRC, 2011). The Southwest Monsoon heavily influences regional climate, 12 resulting in a rain and flood pulse in the Mekong River and its tributaries occurring annually 13 from roughly May to October (MRC, 2012; Figure 2). 


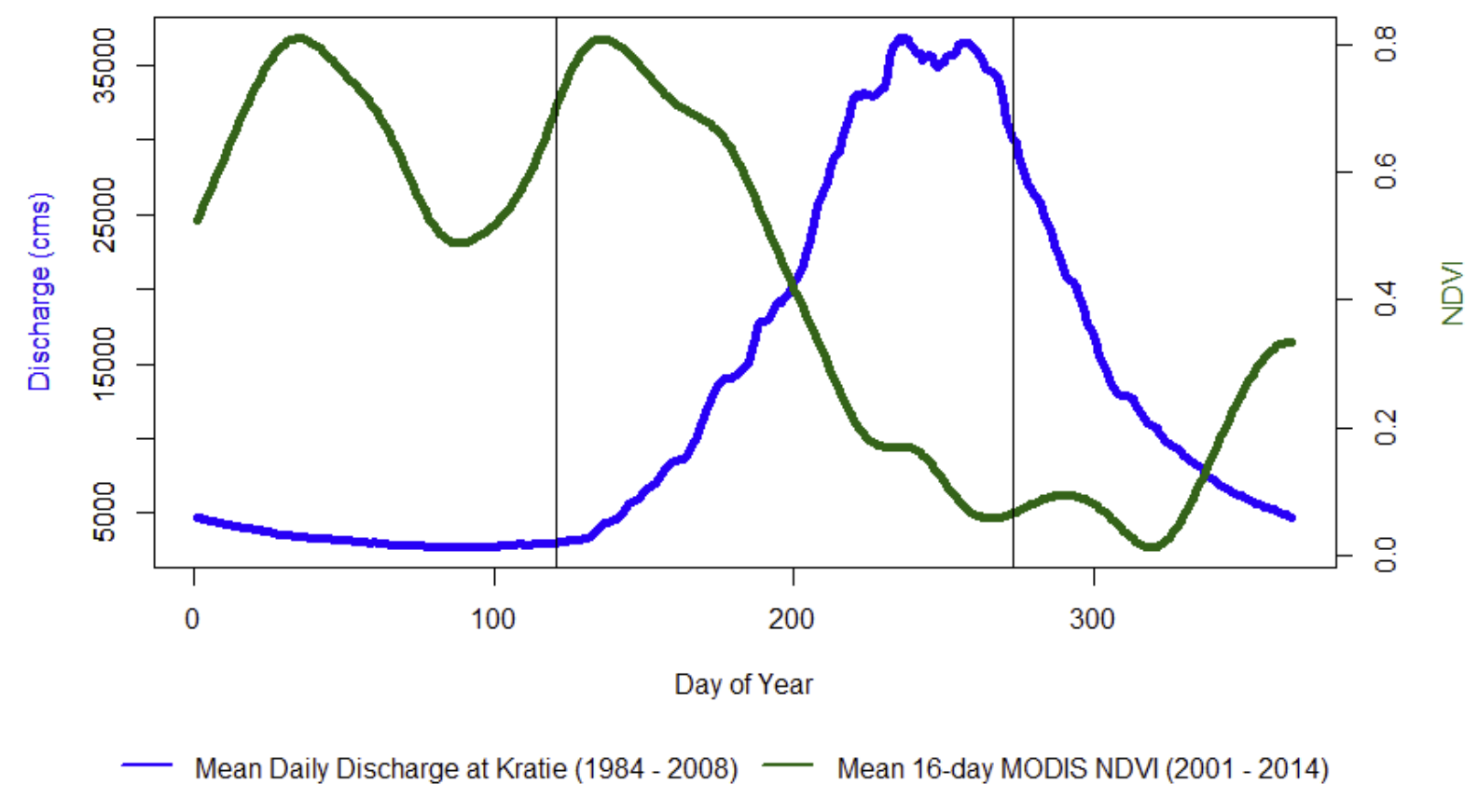

Figure 2: Changes in discharge measured at Kratie (blue; 1984 - 2008) and NDVI (green;

$32001-2014)$ as a function of day of the year. Vertical lines are the days of year shown in 4 Figure 1 (May $1^{\text {st }}$ and September $30^{\text {th }}$ ).

6 Annual flooding provides fertile, nutrient rich sediment which fuels half the world's rice production (Mainuddin et al., 2011). The Mekong also contains the world's largest freshwater capture fishery (MRC, 2012), and large areas of aquaculture (Kuenzer et al., 2015). Though the basin is highly adapted to seasonal flooding (ICEM, 2013), sudden onset and extended floods cause direct mortalities and indirect mortalities through reduced agricultural production (USDA, 2013) and prolonged conditions that foster sickness and disease (Davies et al., 2014).

12 Severe floods also damage public infrastructure, affect education attainment and generally 13 sustain poverty (MRC, 2012). An extensive series of built and planned hydropower projects further complicates the regional hydrologic regime, exacerbating flood risks and uncertainties

15 (Kuenzer et al., 2013; Kuenzer et al., 2013; Räsänen et al., 2017).

16 Southeast Asian countries rely heavily on agriculture and fishing as main staples of their 17 economy. Rice is the main agricultural commodity in terms of production and consumption, and large portions of the total labor force were employed in the agricultural sector as of 2013 (FAOSTAT, 2014). Annual fish catch levels are estimated greater than 2.6 million tons with annual value exceeding \$1.7 billion USD (Van Zalinge et al., 2004). Between 2000 and 2002, 
1 floods depressed agricultural and fish production by $\$ 200-\$ 300$ million USD (MRC, 2014).

2 Flooding in 2011 also caused widespread reductions in crop production and jeopardized

3 regional food security (USDA, 2013). In addition to economic impacts, flooding affects

4 smallholders and subsistence farmers who depend on agriculture and fishing for their

5 livelihoods. Accurate monitoring of surface water extent and inundation frequency can enhance food security and economic vitality in addition to preventing direct loss of life (Mainuddin et al., 2011), which can improve transboundary cooperation and flood risk management in multi-country regions.

Southeast Asia is among the most susceptible regions to the immediate impacts of shifting climatic patterns (IPCC, 2007). The region has experienced sea level rise and intensified flood and drought in the last $30-50$ years (IPCC, 2014). Numerous reports and risk indices (e.g. Global Adaptability Index; World Risk Index) rank Southeast Asian countries among the most vulnerable in the world due to economic dependence on agriculture, large percentages of population living near sea level, and little resilience in the realms of food, water, health, ecosystem services, human habitat and infrastructure (Standard and Poor's, 2014; ND-GAIN, 2015; Birkmann et al., 2014). Information around historic conditions can help countries improve resilience to climate change by better evaluating the severity of past events; while near real-time monitoring systems help reduce the negative impacts of sudden onset hydrologic events. Thus, it is envisaged that improved monitoring, characterization, and understanding of regional flooding will enable better planning and management of these future flood events.

\subsection{Study Objectives and Outline}

In this study, we extend upon previous efforts described in Section 2 to develop an operational, optimized MODIS-based water extent tool for the Lower Mekong River Basin. Section 3 describes the methodology for the water classifier calculation and web portal and Section 4 presents results and follow-on work.

\subsection{Near Real Time NASA Imagery and Disaster Response}

29 Moderate Resolution Orbiting Spectroradiometer (MODIS) instruments on Aqua and Terra 30 satellites image the Mekong region twice daily (Nigro et al., 2014) around 10:30 AM and 
1 1:30 PM local time. Numerous studies (Brakenridge and Anderson, 2006, Nigro et al., 2014)

2 have demonstrated the utility of Multispectral MODIS imagery for determining flood extent.

3 The NASA Land, Atmosphere Near real-time Capability for EOS (LANCE;

4 https://lance.modaps.eosdis.nasa.gov/) is a near real-time distribution system for MODIS imagery, offering free and simple file transfer protocol access to imagery at 3-hour latency. Though the region can be persistently cloudy during the monsoon season, clear MODIS satellite overpasses can be used to determine flood extent rapidly and effectively (Nigro et al., 2014). This information can enhance management and decision making in terms of providing aid and determining damages to infrastructure (e.g. Ahamed et al., 2017), which is currently based on very little or sometimes no accurate information (IFRC, 2013; Raza et al., 2014). Remote sensing information systems described in this study can provide imagery and analysis access to decision makers confronted with a sudden or unexpected onset flood event. The strength of the system described here is that it enables rapid assessment of regional conditions in near real-time, which can enable the application of higher resolution data and focused analysis in areas of interest.

The system uses MODIS-based optical and Near Infrared (NIR) data exclusively (MOD09Q1; MOD09GQ; MOD35). It is well known that water, vegetation, and other land cover exhibit characteristic spectral signatures in optical imagery and can be classified accurately from satellite imagery (Zin and Williams, 1997). The Normalized Difference Vegetation Index (NDVI; Tucker, 1979) is a commonly used index useful for characterizing features on the land surface. NDVI is calculated using the formula:

$N D V I=\left(\frac{\mathrm{NIR}-\mathrm{Red}}{\mathrm{NIR}+\mathrm{Red}}\right)$

where Red is MODIS Band 1 surface reflectance $(620-670 \mathrm{~nm})$ and NIR is MODIS Band 2 surface reflectance $(841-876 \mathrm{~nm})$. Though NDVI is typically used to measure vegetation greenness, it has been used successfully in identifying surface water, particularly in Southeast Asia (Sanyal and Lu, 2004; Xiao et al., 2006).

Typical NDVI values of water range from $-0.1-0.1$, while typical NDVI values of vegetation and agricultural areas are $0.3-1.0$ (Zin and Williams, 1997). As such, decreases in NDVI relative to typical conditions (e.g. from 0.5 to 0.1 ) can be inferred to signify transition from dry land surface to standing water (Fayne et al., 2017). Figure 2 depicts variations in 
1 discharge and NDVI as a function of time, and illustrates decreases in NDVI during monsoon

2 conditions. This characteristic response can be exploited to detect flooded areas and is

3 employed in the methodology described below. Other spectral indices were considered in this

4 analysis but found to offer little improvement to NDVI based methods (e.g. Frazier and Paige,

5 2000; Fayne et al., 2017). Since MODIS bands 1 and 2 are the only bands available at $250 \mathrm{~m}$

6 resolution, other indices derived from MODIS imagery also suffer from decreased spatial

7 resolution ( $500 \mathrm{~m}$ or $1000 \mathrm{~m}$ as opposed to $250 \mathrm{~m}$ ), making them less attractive for community

8 level disaster response.

9

\subsection{Training a Dynamic Surface Water Classifier}

11 The statistical distribution of permanent water NDVI values (e.g. Carroll et al., 2009;

12 MOD44W; Figure 3) are used along with 8-day MODIS climatologies to train classifiers

13 which are subsequently applied to a historic or near real-time image of interest. 


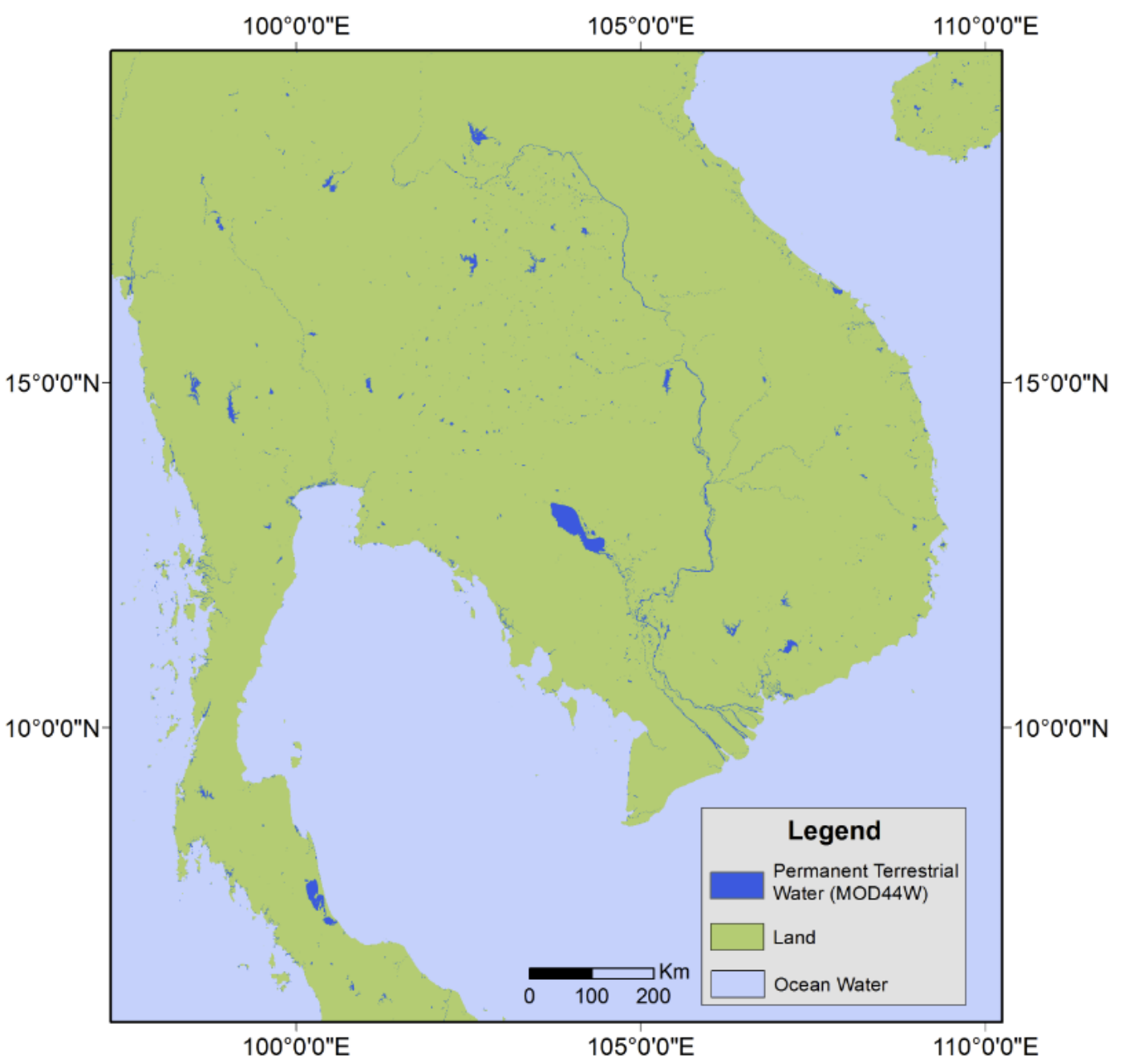

2 Figure 3: Terrestrial permanent water pixels (MOD44W; dark blue) used with MODIS 3 climatology (e.g. Figure 1 left panel) to generate NDVI statistics describing surface water 4 bodies. Aggregated statistics are used to classify surface water in a given image.

6 The system developed for this study accesses the MODIS data archive, downloads all Aqua 7 and Terra 8-day surface reflectance data (MOD09Q1) for a specific day (input by user, or 8 today's date for the near real time system), constructs a climatology based on that day, and 9 determines the mean and standard deviation NDVI values of permanent water bodies (Figure 10 4). Clouds are masked using the MOD/MYD09A1 QA cloud mask bitfields (Vermote, 2016). 11 The mean NDVI value of permanent water (MOD44W) is calculated from the cloud-filtered 12 MODIS climatology using the formula:

$13 \quad N D V I_{\text {mean }}=\frac{1}{k} \sum_{i=0}^{k} N D V I_{P W}$ 
1 Where $k$ is the total number of permanent water pixels and $N D V I_{P W}$ is the per-pixel NDVI

2 value.

3 Standard deviations of permanent water NDVI values are calculated using the formula:

$4 \quad N D V I_{S D}=\sqrt{\frac{1}{k} \sum_{i=0}^{k}\left(x_{i}-N D V I_{\text {mean }}\right)^{2}}$

5 Where $k$ is the total number of permanent water pixels, $x_{\mathrm{i}}$ is the per pixel NDVI value of

6 permanent water pixels, and $N D V I_{\text {mean }}$ is the mean surface water NDVI value described in

7 formula 2.

8 Surface water (SW) is then classified using the formula:

9

$S W \in N D V I_{p x}<\left(N D V I_{\text {mean }}+\frac{N D V I_{S D}}{2}\right)$

10 Where $\mathrm{SW}$ is the set of all pixels $\left(\mathrm{NDVI}_{\mathrm{px}}\right)$ with NDVI values less than $1 / 2$ standard deviation

11 above the mean $\left(N D V I_{\text {mean }}+N D V I_{S D} / 2\right)$. Calibration was performed using an analysis of

12 variance of NDVI of surface water during significant flood events in the study domain and

13 comparison of results across a number of different classification methods using various

14 spectral indices (e.g. Fayne et al., 2017). Figure 4 shows the NDVI distribution of all

15 permanent water pixels for all MODIS images acquired on September $30^{\text {th }}$ for the duration of 16 the MODIS record.

\section{Permanent Water NDVI (Terra MODIS) on September 30 (2000-2015)}

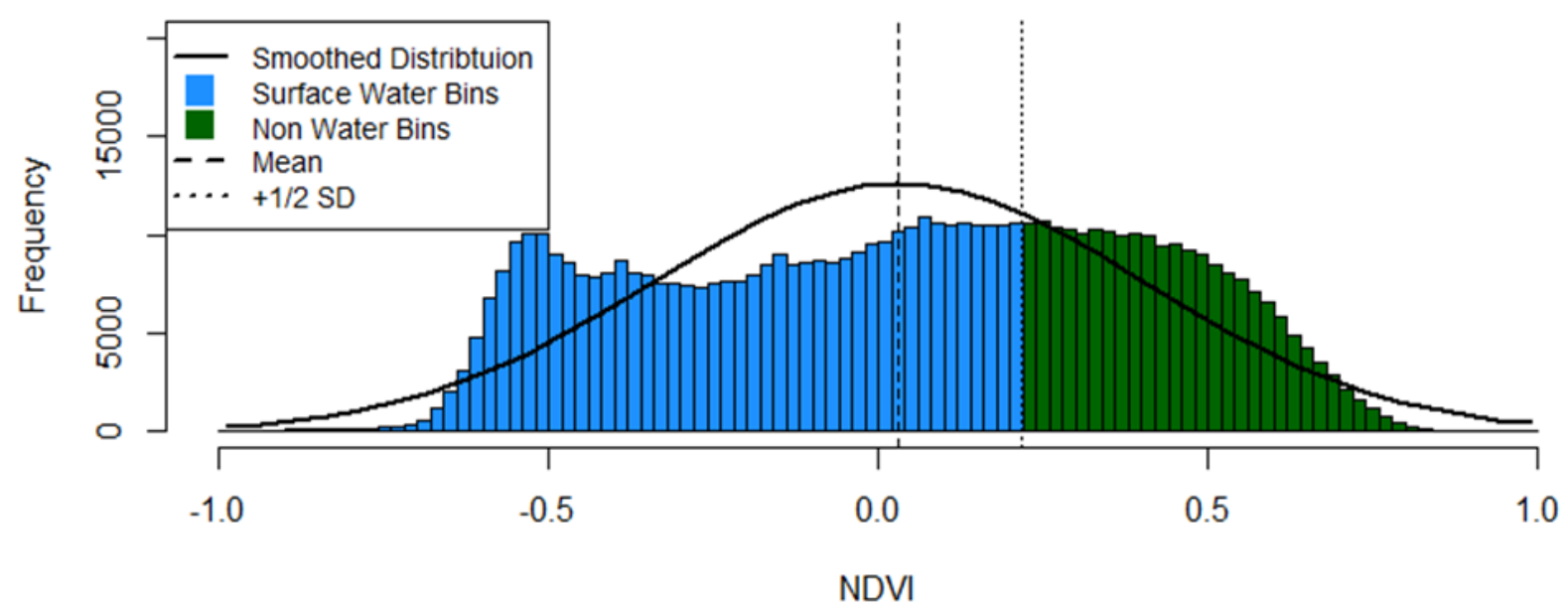

18 Figure 4: Histogram of NDVI values for terrestrial permanent water pixels on September $30^{\text {th }}$ 19 for the MODIS record (2000 - 2015). Blue bins denote NDVI values used as surface water 
1 classifiers, while green bins show non-water classification values. The dashed line shows the mean of the distribution (Equation 2) while the dotted line represents the mean plus $1 / 2$ standard deviation (Equation 3). The dotted line is the upper limit used to classify surface water for each date.

Climatologies change dynamically depending on the day of interest and encapsulate data from 216 - 232 MODIS images depending on the input date and how it corresponds to the start of data acquisition by MODIS Terra and Aqua. The data required to generate Figure 4 and classify an image acquired during a similar time period are computed for each 8-day period of the year and archived in a database for future analysis. It is noted that NDVI signals over permanant water typically will not vary significantly from day-to-day. However, NDVI shows seasonal variations for factors like water depth, suspended sediment, vegetation growth, and algal growth. Though these quantities vary little from day to day, they can change significantly during longer timescales due to the aforementioned factors.

\subsection{Validation of Surface Water Extent Classification Method}

Performance of the MODIS-based surface water products was assessed by comparing them against various high-resolution Synthetic Aperture Radar (SAR) products for flood and nonflood conditions in 2011 and 2013. It is noted that the radar products are not without error. So instead of a traditional validation, per se, this analysis provides a robust demonstration of relative accuracy by comparing several million pixels over various conditions of wetness and terrain. Radar platforms used for validation are shown in Table 1 and include ENVISAT Advanced Synthetic Aperture Radar (Gardini et al., 1995; ASAR, Wide Swath Mode: 150m resolution), Radarsat-2 (Morena et al., 2004; 26m resolution), TerraSAR-X (http://www.dlr.de/eo/en/desktopdefault.aspx/tabid-5725/9296_read-15979; 16m resolution) and the Disaster Monitoring Constellation (da Silva Curiel et al., 2005; DMC; 22m resolution). Data was accessed from the Humanitarian Data Exchange, managed by the United Nations Office for the Coordination of Humanitarian Affairs (https://data.humdata.org/search? $\mathrm{q}=$ cambodia+flood). Metadata for imagery was accessed through the United Nations Institute for Training and Research (http://conference.unitar.org/unosat/aggregator/sources/29). These radar-derived flood extent products were vetted by Hahn Jung, NASA Goddard Space Flight Center, who obtained 
1 comparable results when running Iso and threshold based unsupervised classification

2 algorithms on the raw imagery (personal communication).

3 Confusion matrices are a statistical technique often used in assessment of classification 4 performance, that calculate simple cross-tabulation of the mapped and observed or reference data (Foody, 2002). Confusion matrices, producer's accuracy and user's accuracy (Appendix 1) were calculated for each radar image and corresponding MODIS flood product. In total, 5 synchronous radar and MODIS datasets were analyzed during both flood and non-flood conditions (Table 1). The closest MODIS 8-day composites were used to generate the product and calculate the accuracy statistics. Using ArcGIS software, UNOSAT data describing flood extent were resampled to match MODIS resolution. Confusion matrices and per-pixel producer's and user's accuracy were calculated for each image (Foody, 2002). Cloudy MODIS pixels were omitted. In total, more than 7 million flood and non-flood pixels were considered in the validation (Appendix 1).

\subsection{Surface Water Frequency}

The flood detection algorithm was applied to later stage monsoon seasons (defined here as September $1^{\text {st }}$ to November $30^{\text {th }}$ ) for the length of the MODIS record which contain a daily image from Terra and Aqua for each day of the year beginning in 2003. For each annual monsoon, 8-day surface reflectance images $\left(M^{*} \mathrm{D} 09 \mathrm{Q} 1\right)$ were analyzed for the time period September 1 through November $30^{\text {th }}$ (during which recent and significant floods occurred). Surface water extent was determined on a per pixel basis and the results were aggregated for the duration of the flood season to depict surface water inundation frequency (Figure 7), similar to Kuenzer et al (2015) and Pekel et al (2016).

\subsection{Web Visualization Platform}

An interactive web map visualization platform (http://projectmekongnasa.appspot.com, April $24,2017)$ was created to visualize the near real time component of the analysis. The system is built using the Google Maps Javascript API, Geoserver (http://geoserver.org, April 24, 2017) backend, Python flask framework, and headless Ubuntu 14.04 virtual machine provided by the Open Science Data Cloud (https://www.opensciencedatacloud.org/, April 24, 2017) to 
1 house all software and data. Supplemental hydrologic layers like precipitation, modeled flood

2 potential (available at: https://pmm.nasa.gov/data-access/downloads, April 24, 2017), dam

3 locations, and gauge stations can also be visualized on the map interface (Figure 9).

\section{Results}

6 Validation indicates the algorithm described in Section 3 is comparable in accuracy to higherresolution sensors. Overall agreement for all dates ranged from 79\% - 98\% (Table 1), with an average overall accuracy of $87.3 \%$. Average producer's agreement was $83.4 \%$ while the average user's agreement was 85.3\% (Appendix 1). More than 7 million pixels were considered in the validation exercise. Due to limited data availability, non-flood validation could only be completed for Envisat ASAR and DMC. MODIS products encompassing the radar acquisition date were selected so as to minimize temporal effects.

\begin{tabular}{|c|c|c|c|c|c|}
\hline Platform & Envisat ASAR & Envisat ASAR & Radarsat -2 & TerraSAR-X & DMC \\
\hline Conditions & Flood & Non - Flood & Flood & Flood & $\begin{array}{l}\text { Non - } \\
\text { Flood }\end{array}$ \\
\hline $\begin{array}{l}\text { Overall } \\
\text { Agreement } \\
(\%)\end{array}$ & 88.9 & 79.5 & 89.0 & 80.9 & 98.3 \\
\hline Resolution & $150 \mathrm{~m}$ & $150 \mathrm{~m}$ & $26 \mathrm{~m}$ & $10 \mathrm{~m}$ & $22 m$ \\
\hline $\begin{array}{l}\text { Producer's } \\
\text { Agreement }\end{array}$ & 88.4 & 74.8 & 81.8 & 81.0 & 90.1 \\
\hline $\begin{array}{l}\text { User's } \\
\text { Agreement }\end{array}$ & 88.4 & 78.7 & 88.5 & 8.07 & 90.0 \\
\hline Date & $9 / 30 / 2011$ & $6 / 21 / 2011$ & $10 / 26 / 2013$ & $10 / 23 / 2013$ & $2 / 1 / 2013$ \\
\hline Data URL & $\begin{array}{l}\text { http://floods.unosat. } \\
\text { FP01/FL20111012KH }\end{array}$ & $\begin{array}{l}\text { org/geoportal/ } \\
\text { M.gdb.zip }\end{array}$ & $\begin{array}{l}\text { http://floods } \\
\text { 1/FL2013102 }\end{array}$ & $\begin{array}{l}\text { unosat.org/gec } \\
\text { LHM.gdb.zip }\end{array}$ & portal/FPO \\
\hline
\end{tabular}

14 Table 1: Summary of data sources used in validation and overall agreement with MODIS 15 surface water extent products.

17 Figure 5 shows a spatial comparison of MODIS derived floodwater (red) overlain on an 18 ENVISAT ASAR image, both acquired on September $30^{\text {th }}$, 2011. Darker areas on the radar 19 image indicate surface water. Permanent water pixels (MOD44W) are shown in blue and 20 MODIS-based floodwater is shown in red. Pixels near the Vietnam Delta in the southern 
1 portion of the image could not be classified due to persistent cloud cover. Most of the 2 inaccuracies are omissions as opposed to commissions.

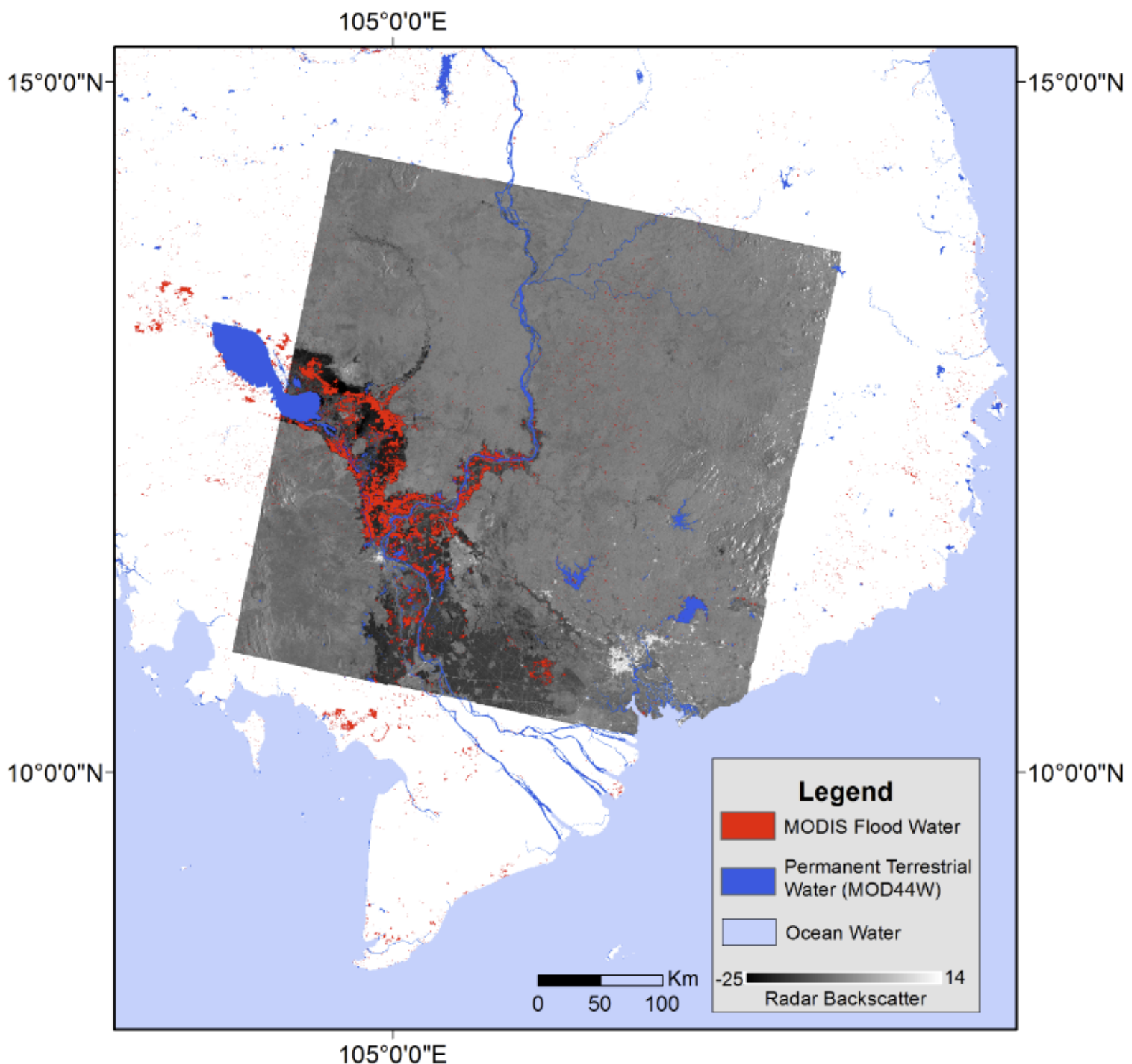

5 Figure 5: Spatial comparison of MODIS flood extent (250m resolution) with ENVISAT 6 ASAR imagery (150m resolution) on September $30^{\text {th }}, 2011$. Floodwater (MODIS) is shown in 7 red. Permanent water is shown in blue. Agreement between the images is about $88 \%$ (Table 8 1). Cloudy MODIS pixels account for the lack of classified floodwater in the southern portion 9 of the image, and are not shown. 


\section{$1 \quad 4.1$ Surface Water Classification}

2 Figures 6-7 show NDVI (top panels) and surface water extent (bottom panels) for October $324^{\text {th }}$ of the MODIS record from 2001-2015 (left panels) and the 8-day composite acquired on 4 October $24^{\text {th }}, 2011$ (right panels). Figure 5 shows the Tonle Sap and Mekong Delta region of 5 Cambodia and Vietnam while Figure 6 shows Thailand just north of Bangkok. The average 6 permanent water MODIS NDVI value is 0.041 (e.g. similar to Figure 4 for October $24^{\text {th }}$ ), 7 which is a typical NDVI value for water (Zin and Williams, 1997). The standard deviation of 8 permanent water NDVI is 0.452 (Figure 4). Therefore, pixels with a NDVI value less than 90.227 are classified as surface water (Section 2.1). The large range and bimodal distribution 10 of NDVI values shown in Figure 4 suggests that some permanent water pixels are actually 11 vegetated or partially vegetated in standing water. This finding highlights the need for an updated MOD44 permanent water mask product (Carroll, 2009), which is under development at NASA Goddard Space Flight Center.
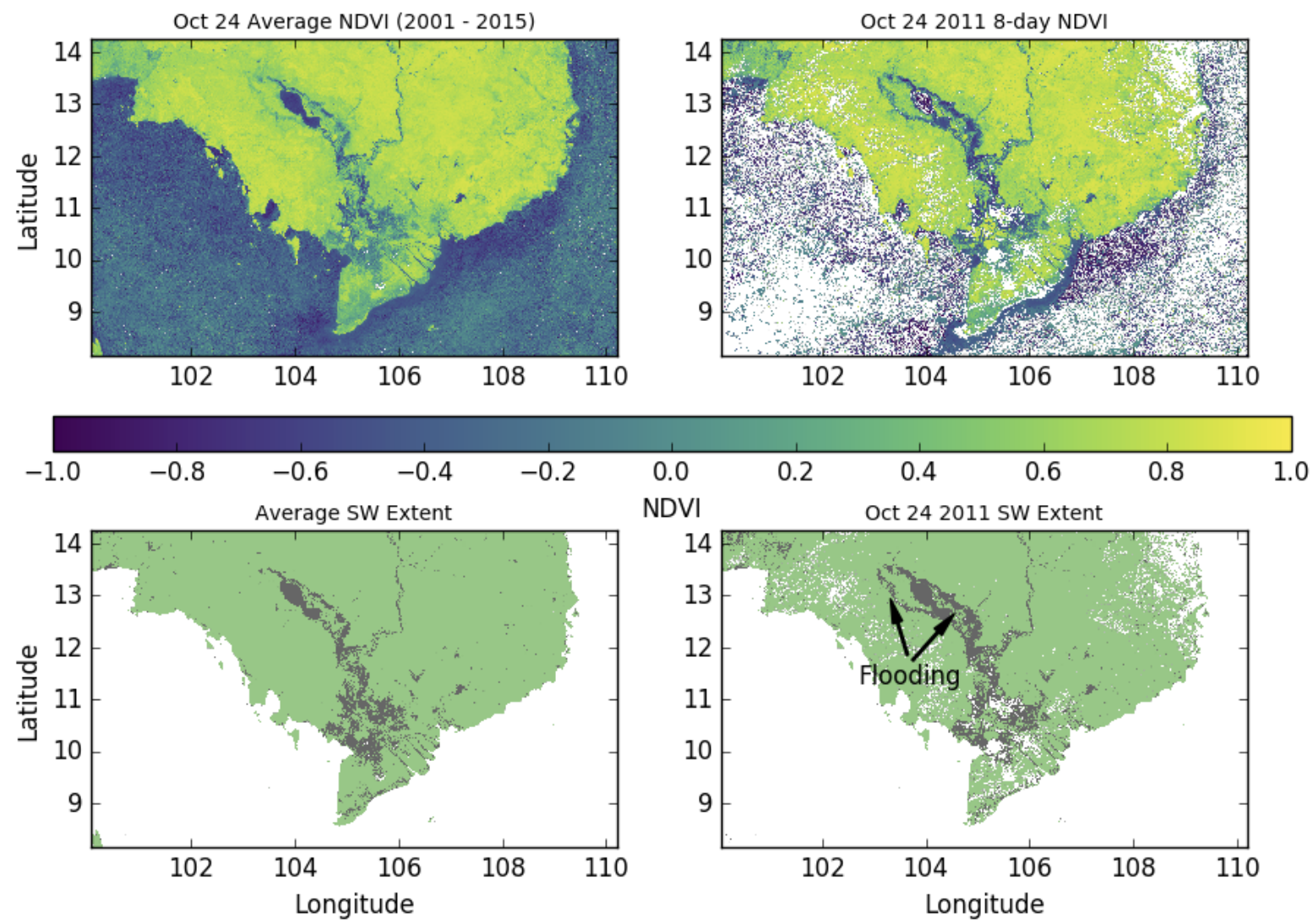

15 Figure 6: NDVI (top panel) and Surface Water extent (bottom panel) for the Tonle Sap and

16 Mekong Delta regions. Average NDVI values for the length of the MODIS record are shown 17 on the top left image and the October 24, 2011 8-day composite is shown in the top right 
1 image. The bottom panels show surface water extent using permanent water NDVI

2 thresholding for the length of record (bottom left) and the October 24, 2013 8-day composites

3 (bottom right). Clouds and ocean water are masked and shown in white.
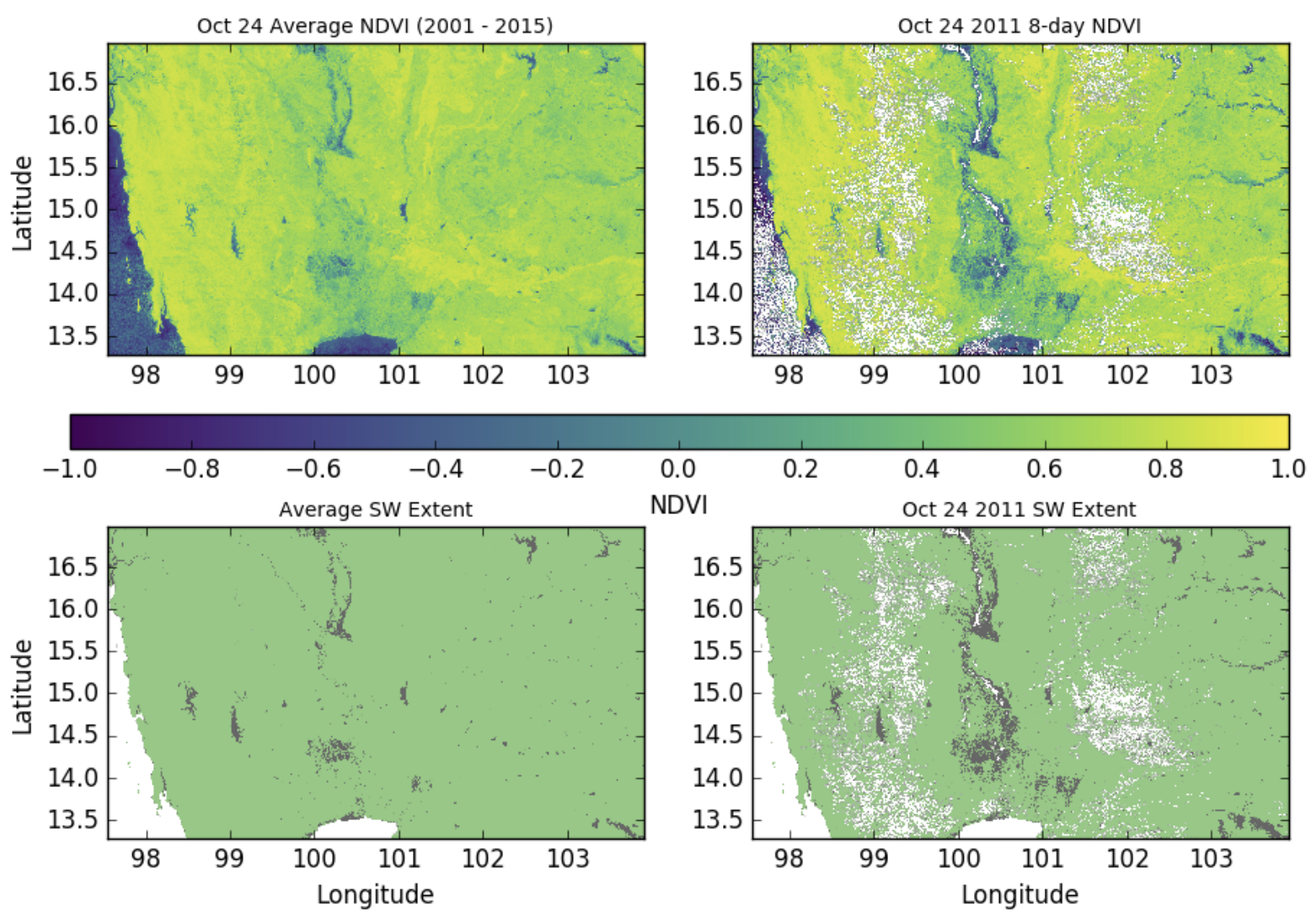

5 Figure 7: NDVI (top panel) and Surface Water extent (bottom panel) for Thailand. Average

6 NDVI values for the length of the MODIS record are shown on the top left image and the October 24, 20118 -day composite is shown in the top right image. The bottom panel shows surface water extent using permanent water NDVI thresholding for the length of record (bottom left) and the October 24, 2013 8-day composites (bottom right). Clouds and ocean water are masked and shown in white.

\subsection{Surface Water Frequency}

12 Complex regional monsoon inundation patterns found in Southeast Asia are illustrated in

13 Figure 8 for the case of the Mekong Delta in Vietnam and Figure 9 for the case of the Chao

14 Phraya delta in Thailand. Pekkel et al., (2016) obtained spatially similar results for both areas

15 shown in Figure 8 and 9 respectively. Similar temporal dynamics are described in Kuenzer et 16 al., $(2013,2015)$ who report comparable accuracy statistics for flood classification in the 
1 Mekong Delta, Ganges-Brahmaputra Delta, and other major river deltas throughout the world

2 (Kuenzer et al., 2015).

Monsoon Season Surface Water Frequency (2003 - 2015)
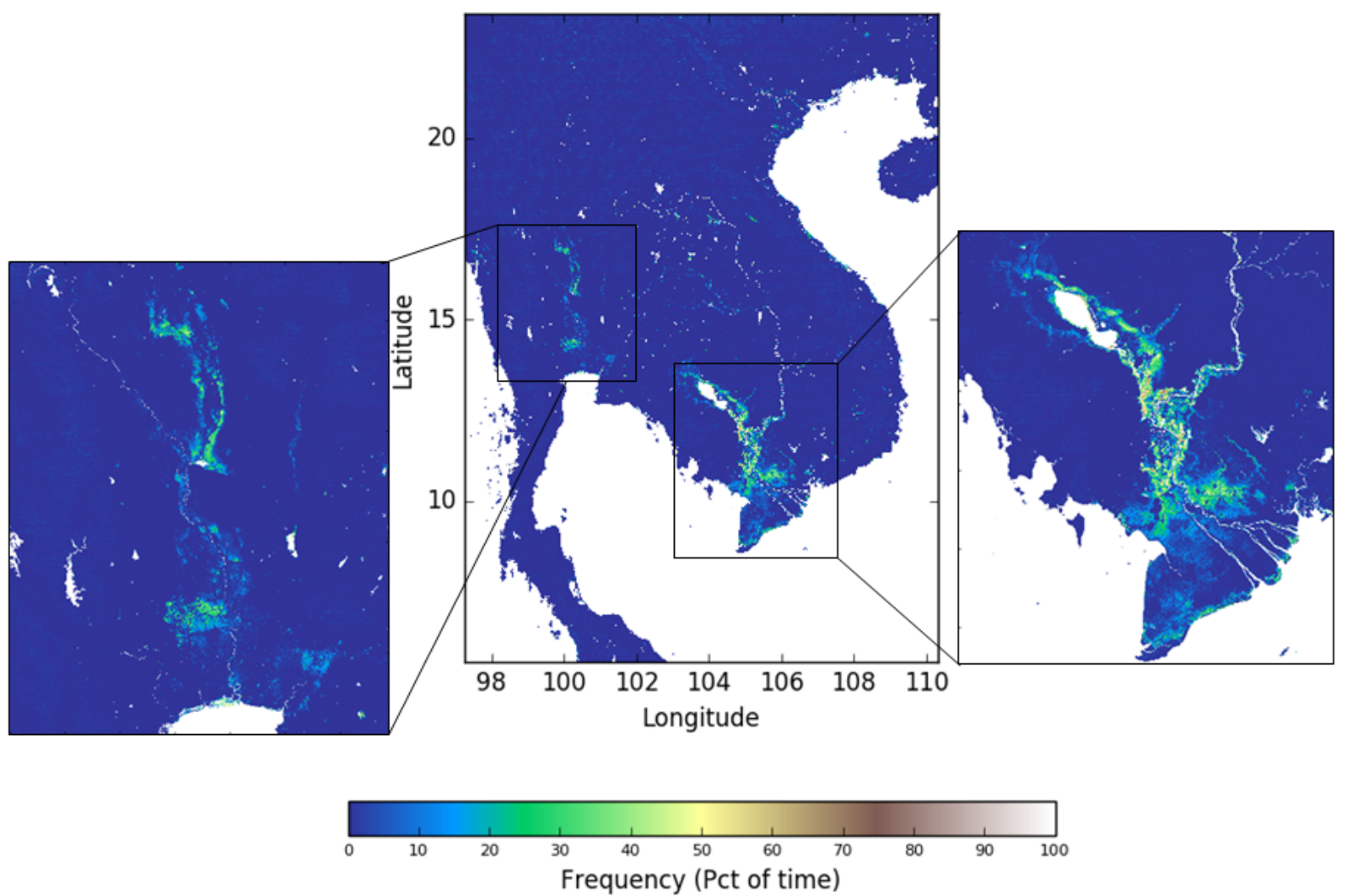

3

These surface water frequency maps can help inform urban planning and agricultural decisions by illustrating water frequency and highlighting spatial and temporal inundation trends that are not visible on inter-annual timescales (e.g. Donchyts et al., 2016; Pekkel et al., 2016). Similarly, surface water can be determined for each 8-day (or daily) period during a specific monsoon season to gain insight about the spatial and temporal evolution of a specific event or monsoon season. Figures 9-10 show surface water extent during the 2011 and 2013 monsoon seasons, during which destructive and widespread flooding occurred. The time series plots at the bottom of each figure show temporal distribution of flooded pixels within the domain. Figure 9 shows the flood impact of the 2011 monsoon and suggests an extended duration flood, with the flood fraction remaining one standard deviation above the average for 
1 many months. Figure 10 shows the 2013 monsoon season and suggests a sudden onset flood

2 since only one 8-day period of the monsoon season exceeds one standard deviation above the

3 flood fraction. Both events caused widespread loss of life and damage to infrastructure (, 4 April 24, 2017).

\section{Monsoon Season Surface Water}

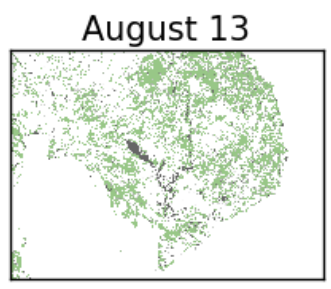

September 6

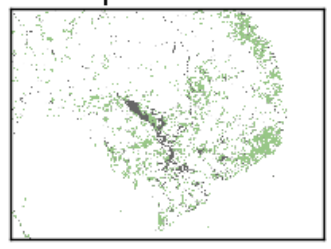

September 30

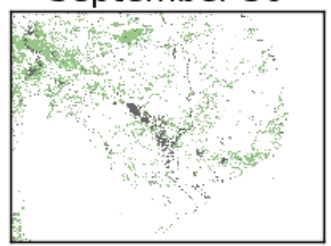

October 24

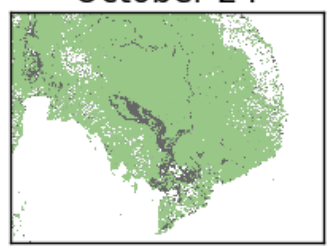

August 21

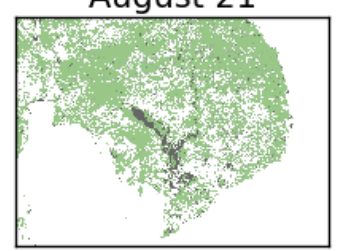

September 14

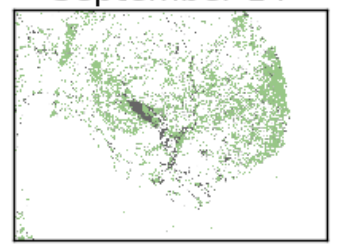

October 8

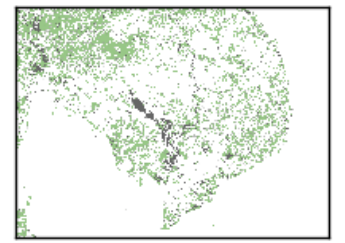

November 1

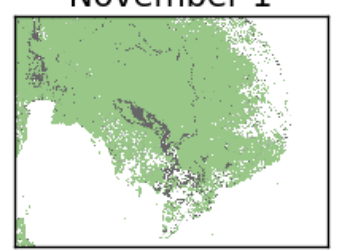

August 29

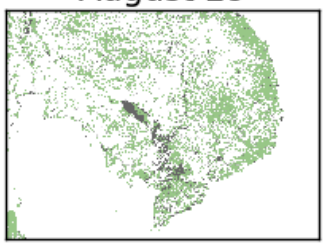

September 22

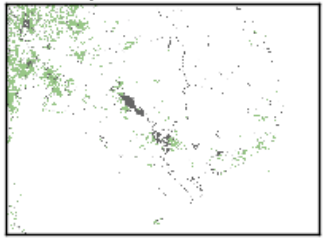

October 16

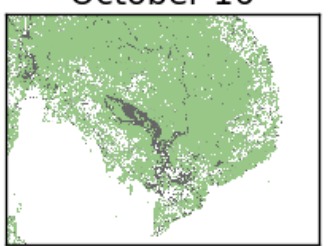

November 9

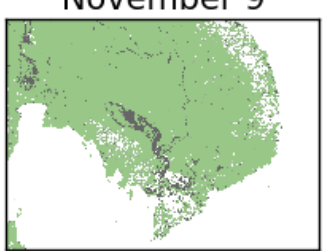




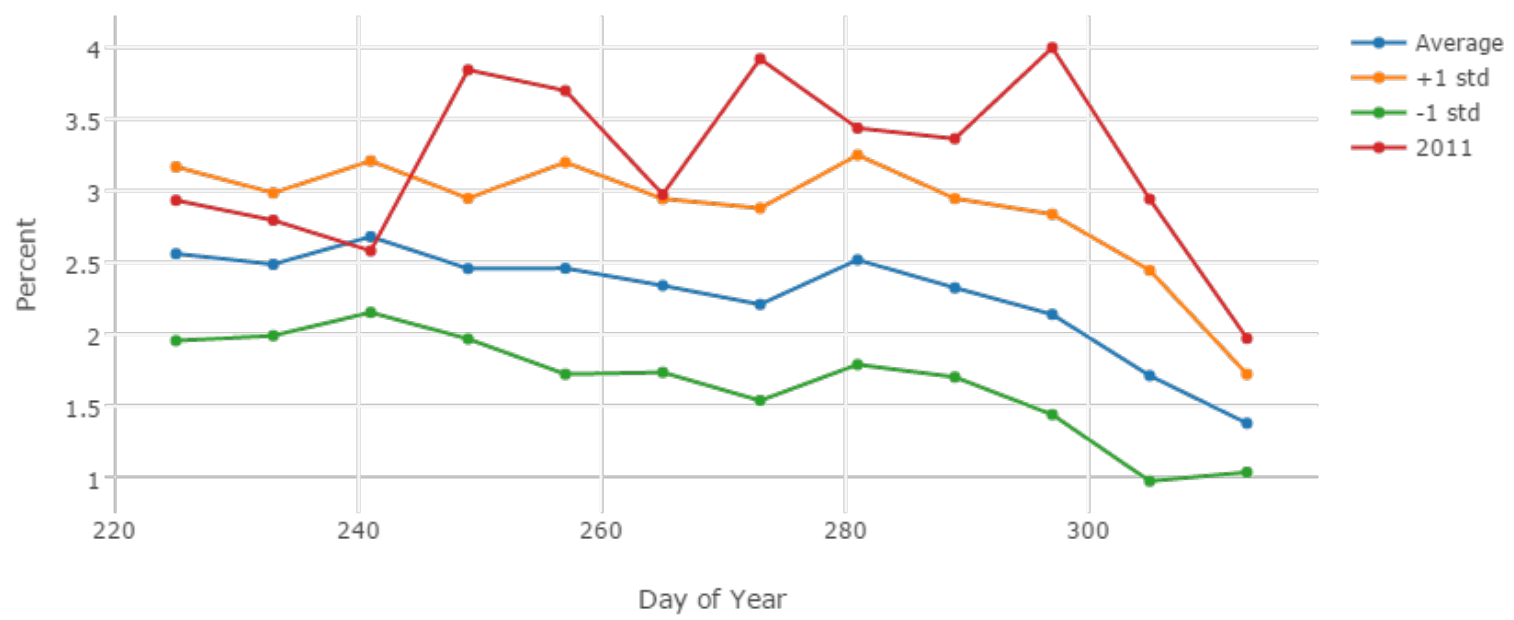

2 Figure 9: Map showing surface water distribution for dates during the 2011 monsoon season 3 (top) and time series plot showing total percent of surface water pixels relative to all classified 4 pixels as a function of time (bottom). Clouds are shown in white on maps and eliminated from 5 data used in lower time series plot. Surface water pixel percentage exceeds 1 standard 6 deviation above the mean for the majority of the monsoon season (Day of Year 241; August $729^{\text {th }}$ onward), suggesting an extended duration flood. 


\section{Monsoon Season Surface Water}

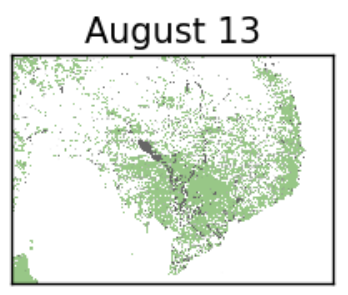

September 6

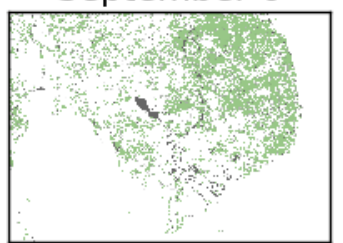

September 30

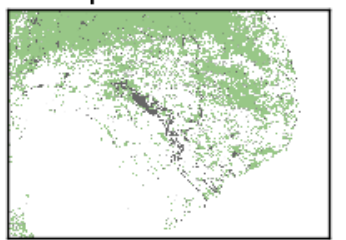

October 24

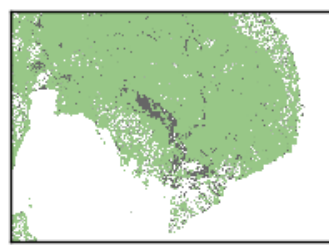

August 21

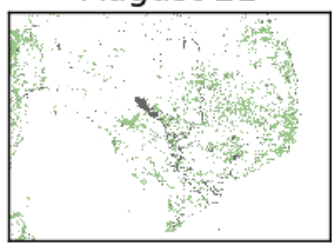

September 14

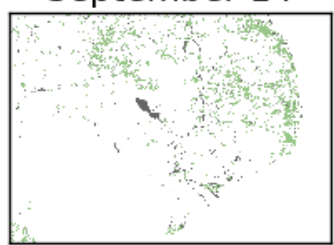

October 8

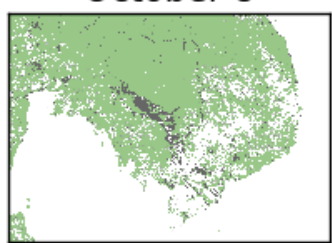

November 1

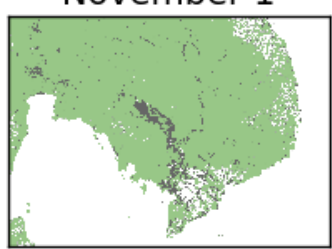

August 29

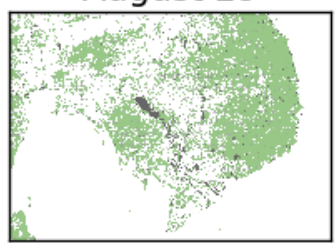

September 22

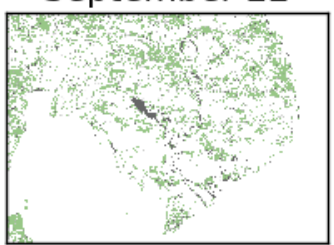

October 16

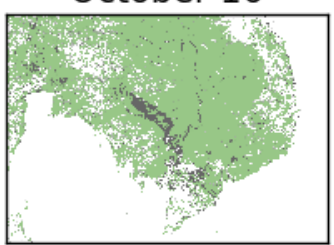

November 9

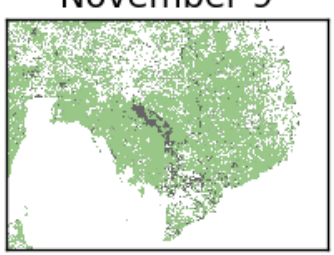

Percent of total pixels marked Flood Water

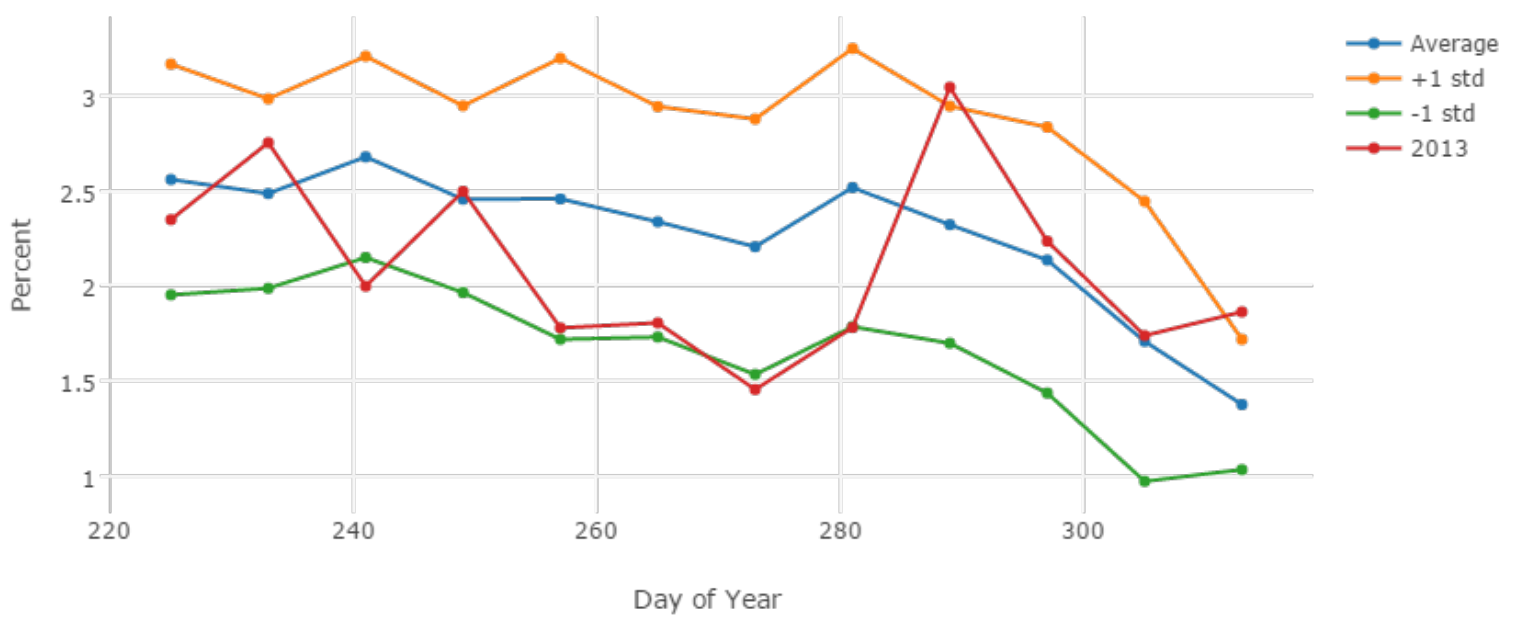

3 Figure 10: Map showing surface water distribution for dates during the 2013 monsoon season

4 (top) and time series plot showing total percent of surface water pixels relative to all classified

5 pixels as a function of time (bottom). Clouds are shown in white on maps and eliminated from 
1 data used in lower plot. Surface water pixel percentage exceeds 1 standard deviation above

2 the mean for only one week of the monsoon season (Day of Year 289; October $16^{\text {th }}$ ), 3 suggesting a sudden onset flood.

\section{$5 \quad 4.3 \quad$ Near Real-Time System and Web Visualization Platform}

6 Classification methods described in Section 2 are visualized on a near real-time surface water 7 monitoring system which continually ingests the latest Aqua and Terra imagery at 3 hour 8 latency to provide daily $250 \mathrm{~m}$ flood extent. Near real-time observations filter out clouds based on MOD35 cloud product and composite observations in 4-day increments to minimize cloud cover. Previous studies (e.g. Chen et al., 2013) have found no difference in quality between

11 daily and 8-day imagery in the context of surface water mapping, allowing extrapolation of 12 the method from historic and composited to daily and near real-time imagery.

13 Operationally configured in Fall 2016, the system was able to detect flooding occurring in 14 Central Thailand $\left(10 / 2016\right.$; near $\left.17^{\circ} \mathrm{N}, 107^{\circ} \mathrm{W}\right)$, Coastal Vietnam $\left(11 / 2016\right.$; near $17^{\circ} \mathrm{N}$, $\left.15100^{\circ} \mathrm{W}\right)$, and Southern Thailand $\left(1 / 2017\right.$; near $\left.8^{\circ} \mathrm{N}, 100^{\circ} \mathrm{W}\right)$ during the later stages of the 16 monsoon and early stages of the dry season (e.g. Figure 11). Software tools are being distributed to regional agencies like the Mekong River Commission and Asian Disaster 18 Preparedness Center as part of a collaborative project with NASA, The United States 19 Geological Survey (USGS), and United States Agency for International Development 20 (USAID). 


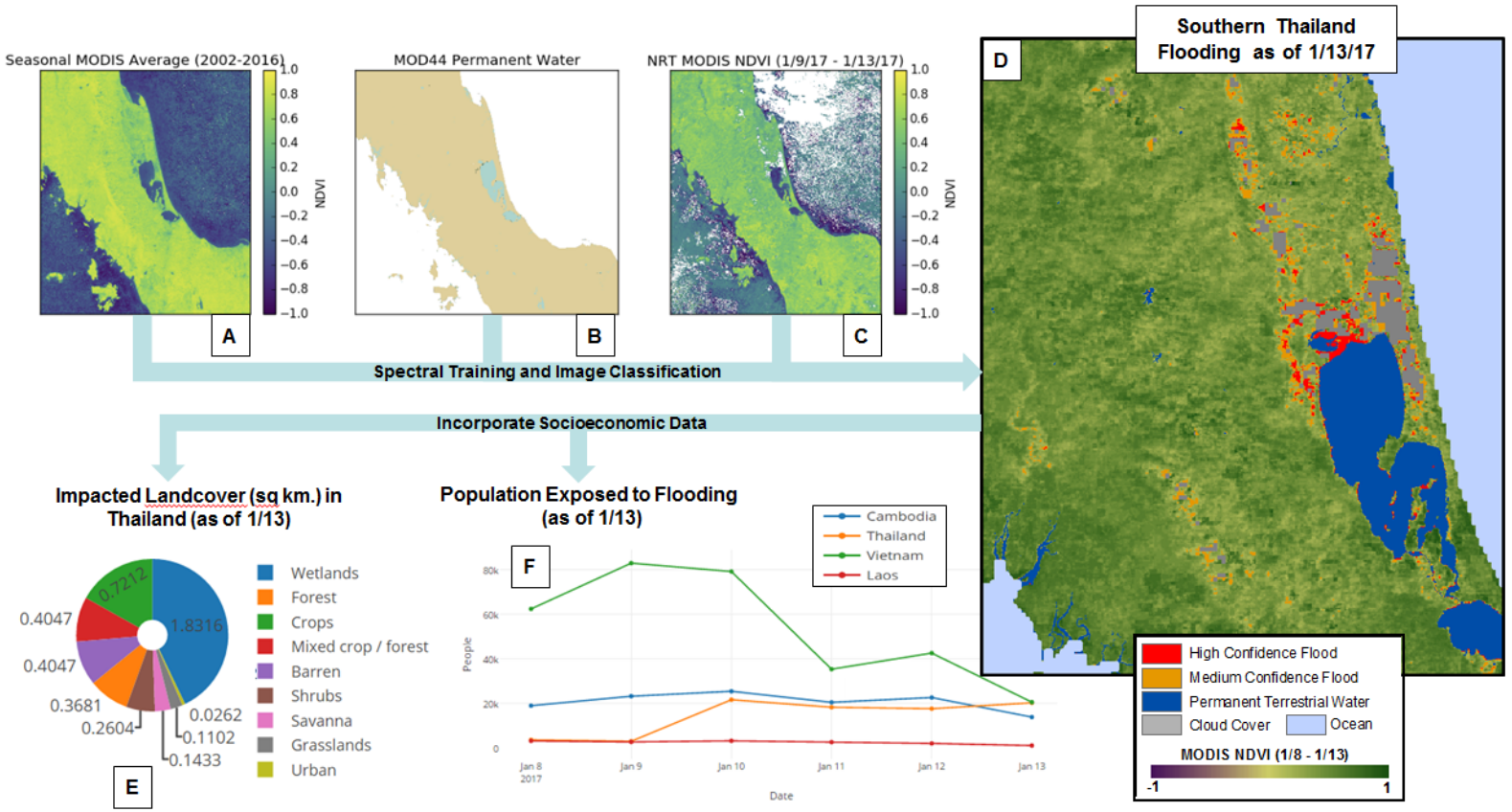

2 Figure 11: Schematic of data processing pipeline depicting (A) MODIS Climatology, (B) 3 Training data, (C) Input Image, (D) Classified image, (E) Landcover (MOD12Q1) of flooded 4 pixels in Thailand, (F) Cumulative population residing in flooded pixels for each country in 5 Southeast Asia (Note increase in Thailand impacted population for January 10). This diagram 6 depicts the operational system's successful detection of flooding in Southern Thailand (D), 7 occurring in early 2017 , and associated data products to be discussed in a later study (E and 8 F). 


\section{Realtime Hydrologic Conditions in Southeast Asia}

Products and website currently under development at NASA Goddard Space Flight Center
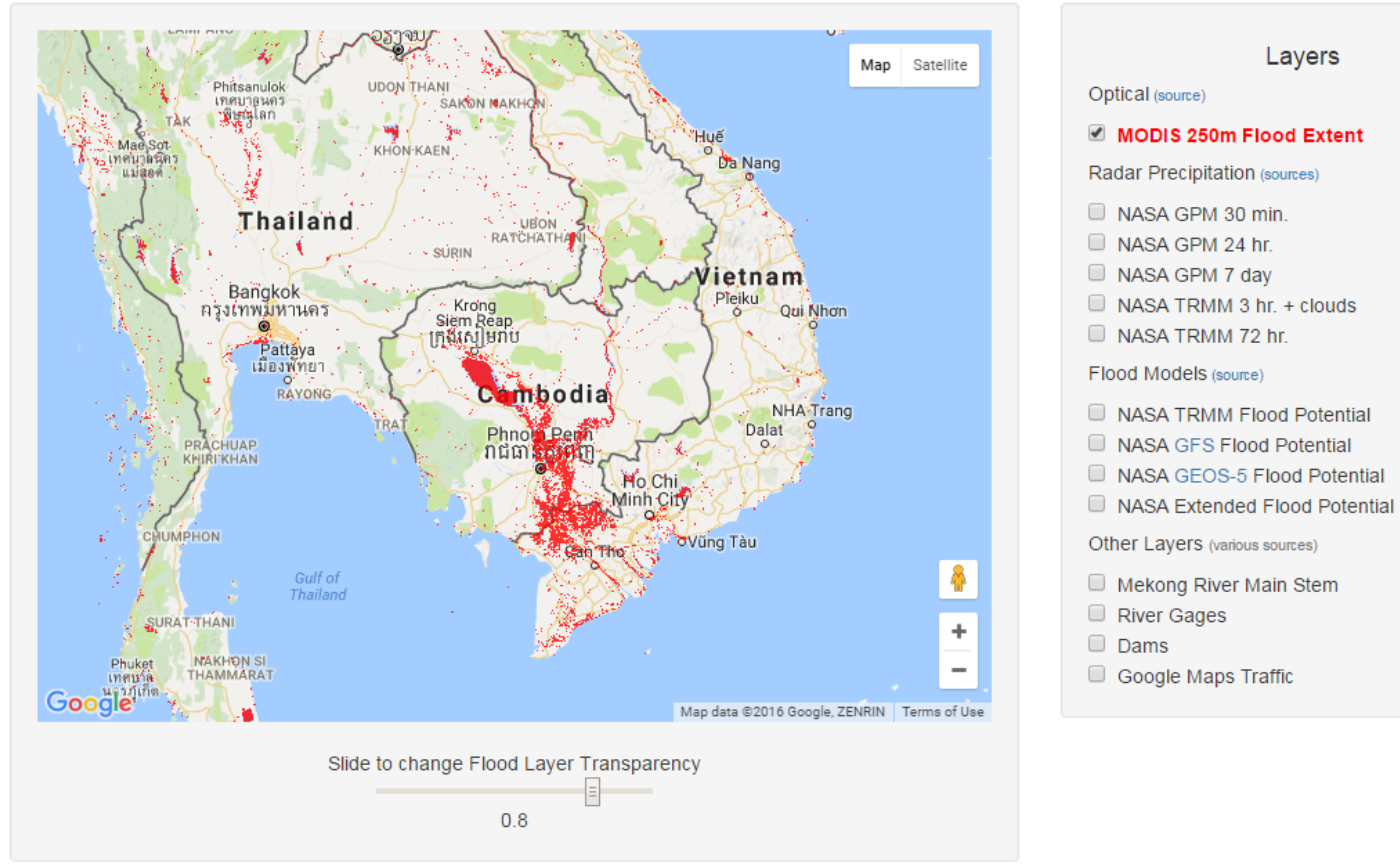

2 Figure 12: Screenshot near real-time surface water monitoring interface. Maximum surface water extent for 2013 flooding is shown as an example. Additional layers describing rainfall, flood potential, dams, and gage stations are also available.

\section{Discussion}

7 Visible and near-infrared MODIS imagery, a readily available and free data source, can be

8 used to accurately classify past and current surface water during flood events in Southeast

9 Asia. Despite various limitations (e.g., signal attenuation from clouds, coarse resolution, etc.), MODIS imagery delivers results comparable to a suite of sampled radar imagery for all tested

11 flood events in the Lower Mekong River Basin. When used with hydrologic routing models and on the ground observations, MODIS imagery and derived products can be a powerful tool to provide an accurate and timely estimate of surface water extent. These findings suggest that

14 MODIS imagery and the techniques described here could be used to direct tasked radar 15 satellite missions during a flood disaster and guide the initial stages of humanitarian aid 
1 efforts carried out by governments and relief agencies both in Southeast Asia and other areas

2 of the world.

3 Even though results are promising, this methodology is subject to a few principal limitations.

4 The algorithms described in Section 3 use the MOD44W (Caroll et al., 2009) water mask to train surface water classifiers, and hence are dependent on the accuracy of this product. The wide distribution of NDVI values for "permanent water" (e.g. Figure 4) indicate that the mask encapsulates some vegetated pixels, namely those with high NDVI values. This may be due to initial misclassification, rivers that have meandered away from former positions, and hydropower construction. However, an updated water mask could easily be substituted for the current product (Kuenzer et al., 2015), and this work is underway.

It is also important to note the impact of cloud cover on data availability and product latency. Cloud cover is a significant challenge since it is not uncommon for atmospheric conditions to obstruct quality observations for days to weeks during the monsoon season. Though compositing routines are used to limit the effects of clouds, there are no guarantees that cloud cover will break during any MODIS overpass. Further, the resolution of MODIS cannot reconcile water bodies smaller than 250 meters. Mixed pixels containing both water and sediment rich water may be misclassified due to similar optical properties to land. Cloud shadows, though accounted for in the MOD09A1 and MOD35_L2 products, also exhibit spectral similarities to surface water. Rice paddy and aquaculture farms are characterized by standing water and hence cannot be differentiated from surface water due to flooding. However, given these limitations, the MODIS-based system described here demonstrates the potentially high impact, near real-time benefit from applying these data. To this end, rapid assessment of the spatial distribution and relative intensity (e.g., Figure 10) of a flood event can be of great value to regional stakeholders.

\section{Conclusion}

The described system is ideal for rapid flood response decision support. When combined with modeled hydrologic data and complimented by other satellite-based data, this automated approach will enable improved management of past and real-time flood events in the region. A possible extension of this work is to combine the flood inundation maps with data that can be used to rapidly assess and possibly mitigate damage to infrastructure, utilities, and crops. The authors are developing an impact assessment system which fuses surface water data with 
socioeconomic datasets (e.g. population, infrastructure, landcover/agriculture) to provide decision support local agencies and the international relief community. Investigatory work for expanding the system to a global scale has begun.

In addition, some of the bi-products of the automated flood inundation mapping system may be useful for stakeholders in the region. Software underlying the system has been transferred to the Asian Disaster Preparedness Center and can be customized depending on specific needs and use cases. The average surface water extent (e.g. Figure 6-7, bottom left panel) derived from MODIS climatologies (e.g. Figure 6-7, top left panel) can help inform agricultural and urban planning applications by providing a regional estimate of impacted areas that can be focused on using finer resolution data such as SAR. It may also be possible for this information to be combined with a Digital Elevation Model (DEM) and other data (e.g. soil moisture) to serve as a decision support tool for resilient infrastructure development. Since the region is likely to face intensified flood and drought in the future, climatological records of vegetation intensity (e.g. Figure 6-7 top panel) and surface water extent (bottom panel) can be used as benchmarks and baselines for future scenarios.

\section{Acknowledgements}

The authors would like to thank Colin Doyle and Jessica Fayne of the NASA DEVELOP program in particular for exploratory research and thoughtful reviews of this paper. Support for this study was provided by the NASA Applied Sciences Program. Partnership and regional expertise of the Mekong River Commission and Asian Disaster Preparedness Center is gratefully acknowledged. Exploratory research was supported by the NASA DEVELOP National Program. We would like to acknowledge the Project Mekong research group, which has consisted of Venkat Lakshmi, Ibrahim Mohammed, Raghavan Srinivasan, Joe Spruce, Manika Gupta, Jessica Fayne, Brent Hall, Tom Doyle, Rick Wilson, and Bogdan Chivoiu. Thanks to Jonathan Spring, Kyle Schmidt, Walt Wells, and Dan Mandl for use of OSDC resources. Thanks to Anika Cartas for assistance in web development. Thanks to Brent Smith, Sean McCartney, Justin Roberts-Pierel, Amanda Rumsey, and others at NASA GSFC for idea exchange, prototyping, and comraderie. This work made use of the Open Science Data Cloud (OSDC) which is an Open Cloud Consortium (OCC)-sponsored project. OSDC is supported in part by grants from Gordon and Betty Moore Foundation and the National Science 
1 Foundation and major contributions from OCC members like the University of Chicago.

2 Thanks to the StackOverflow and the open source community for knowledge exchange.

3

$4 \quad$ Appendix 1: Confusion Matrices

$5 \quad$ Attached as Excel Spreadsheet

6

7

\section{0}

13 Matuschke, I. (2014). World Risk Report 2014.

14

24 Brakenridge, R., Anderson, E., \& Caquard, S. (2006). Dartmouth Flood Observatory. Hanover, USA ((2004). http://www. dartmouth. edu/ floods/). 
1 Carroll, M. L., Townshend, J. R., DiMiceli, C. M., Noojipady, P., \& Sohlberg, R. A. (2009).

2 A new global raster water mask at $250 \mathrm{~m}$ resolution. International Journal of Digital Earth, $32(4), 291-308$.

4

5 Chen, Y., Huang, C., Ticehurst, C., Merrin, L., \& Thew, P. (2013). An evaluation of MODIS 6 daily and 8-day composite products for floodplain and wetland inundation 7 mapping. Wetlands, 33(5), 823-835.

9 Davies, G. I., McIver, L., Kim, Y., Hashizume, M., Iddings, S., \& Chan, V. (2014). Water10 borne diseases and extreme weather events in Cambodia: Review of impacts and implications 11 of climate change. International journal of environmental research and public health, 12(1), $12 \quad 191-213$.

13

14 Donchyts, G., Baart, F., Winsemius, H., Gorelick, N., Kwadijk, J., \& van de Giesen, N. 15 (2016). Earth's surface water change over the past 30 years. Nature Climate Change, 6(9), $16810-813$

Fayne, J. V., Bolten, J.D., Lakshmi, V.,\& Ahamed, A., (2017). Optical and Physical methods for Mapping Flooding with Satellite imagery. Remote Sensing of Hydrological Extremes. 83103.

22 da Silva Curiel, A., Boland, L., Cooksley, J., Bekhti, M., Stephens, P., Sun, W., \& Sweeting, 23 M. (2005). First results from the disaster monitoring constellation (DMC). Acta Astronautica, $56(1), 261-271$.

FAOSTAT, (2014). Statistical Databases. Food and Agriculture Organization of the United Nations. 
1 Foody, G. M. (2002). Status of land cover classification accuracy assessment. Remote sensing

2 of environment, 80(1), 185-201.

3

4 Frazier, P. S., and Page, K. J. (2000). Water body detection and delineation with Landsat TM 5 data. Photogrammetric engineering and remote sensing, 66(12), 1461-1468.

6

7 Gardini, B., Graf, G. and Ratier, G. (1995). The instruments on Envisat.. Acta Astronautica, $8 \quad 37: 301-311$.

9

Huang, C., Chen, Y., \& Wu, J. (2014). Mapping spatio-temporal flood inundation dynamics at

11 large river basin scale using time-series flow data and MODIS imagery. International Journal 12 of Applied Earth Observation and Geoinformation, 26, 350-362.

13

14 ICEM, (2013). USAID Mekong ARCC Climate Change Impact and Adaptation Study for the 15 Lower Mekong Basin: Main Report. International Centre for Environmental Management. 16 https:/www.usaid.gov/sites/default/files/documents/1861/USAID_Mekong_ARCC_Climate 17 Change Impact and_Adaption_Study_Main_Report.pdf

19 IFRC, (2013). World Disasters Report. Focus on technology and the future of humanitarian 20 action. International Federation of Red Cross and Red Crescent Societies. 21 http://www.ifrc.org/PageFiles/134658/WDR\%202013\%20complete.pdf

23 IPCC, (2007). Climate Change 2007: The Physical Science Basis. Contribution of Working 24 Group I to the Fourth Assessment Report of the Intergovernmental Panel on Climate Change 25 [Solomon, S., D. Qin, M. Manning, Z. Chen, M. Marquis, K.B. Averyt, M.Tignor and H.L. 26 Miller (eds.)]. Cambridge University Press, Cambridge, United Kingdom and New York, NY, 27 USA. 
1 IPCC, (2012). Managing the risks of extreme events and disasters to advance climate change

2 adaptation A Special Report of Working Groups I and II of the Intergovernmental Panel on 3 Climate Change [Field, C. B. (Ed.)]. Cambridge University Press, Cambridge, United 4 Kingdom.

Jonkman, S. N., \& Kelman, I. (2005). An analysis of the causes and circumstances of flood disaster deaths. Disasters, 29(1), 75-97.

Jonkman, S. N. (2005). Global perspectives on loss of human life caused by floods. Natural Hazards, 34(2), 151-175.

Kirsch, T. D., Wadhwani, C., Sauer, L., Doocy, S., \& Catlett, C. (2012). Impact of the 2010 Pakistan floods on rural and urban populations at six months. PLoS currents, 4.

Klein, I., Dietz, A., Gessner, U., Dech, S., \& Kuenzer, C. (2015). Results of the Global WaterPack: A novel product to assess inland water body dynamics on a daily basis. Remote Sensing Letters, 6(1), 78-87.

Knox, J. C. (1993). Large increases in flood magnitude in response to modest changes in climate. Nature, 361(6411), 430-432.

Kuenzer, C., Guo, H., Huth, J., Leinenkugel, P., Li, X., \& Dech, S. (2013). Flood mapping and flood dynamics of the Mekong Delta: ENVISAT-ASAR-WSM based time series analyses. Remote Sensing, 5(2), 687-715.

Kuenzer, C., Guo, H., Schlegel, I., Tuan, V. Q., Li, X., \& Dech, S. (2013). Varying scale and capability of envisat ASAR-WSM, TerraSAR-X Scansar and TerraSAR-X Stripmap data to assess urban flood situations: A case study of the Mekong delta in Can Tho province. Remote Sensing, 5(10), 5122-5142. 
2 Kuenzer, C., Klein, I., Ullmann, T., Georgiou, E. F., Baumhauer, R., \& Dech, S. (2015).

3 Remote sensing of river delta inundation: exploiting the potential of coarse spatial resolution, temporally-dense MODIS Time Series. Remote Sensing, 7(7), 8516-8542.

Kussul, N., Shelestov, A., \& Skakun, S. (2011). Flood monitoring from SAR data. In Use of Satellite and In-Situ Data to Improve Sustainability (pp. 19-29). Springer Netherlands.

Noji, E. K. (2005). Public health issues in disasters. Critical care medicine, 33(1), S29-S33.

9

Lauri, H., Moel, H. D., Ward, P. J., Räsänen, T. A., Keskinen, M., \& Kummu, M. (2012).

11 Future changes in Mekong River hydrology: impact of climate change and reservoir operation

12 on discharge. Hydrology and Earth System Sciences, 16(12), 4603-4619.

13

14

Leinenkugel, P., Kuenzer, C., \& Dech, S. (2013). Comparison and enhancement of MODIS cloud mask products for Southeast Asia. International journal of remote sensing, 34(8), 27302748.

Long, N. T., \& Trong, B. D. (2001, November). Flood monitoring of Mekong River delta, Vietnam using ERS SAR data. In A paper presented at the 22nd Asian conference of remote sensing, Singapore (pp. 5-9).

Mainuddin, M., Kirby, M., \& Hoanh, C. T. (2011). Adaptation to climate change for food security in the lower Mekong Basin. Food Security, 3(4), 433-450.

Martinis, S., Twele, A., \& Voigt, S. (2009). Towards operational near real-time flood detection using a split-based automatic thresholding procedure on high resolution TerraSARX data. Natural Hazards and Earth System Science,9(2), 303-314. 
1 Martinis, S., Twele, A., Strobl, C., Kersten, J., \& Stein, E. (2013). A multi-scale flood

2 monitoring system based on fully automatic MODIS and TerraSAR-X processing chains.

3 Remote Sensing, 5(11), 5598-5619.

4

5 Mirza, M. M. Q. (2002). Global warming and changes in the probability of occurrence of

6 floods in Bangladesh and implications. Global environmental change, 12(2), 127-138.

7

8 Morena, L. C., James, K. V., \& Beck, J. (2004). An introduction to the RADARSAT-2

9 mission. Canadian Journal of Remote Sensing, 30(3), 221-234.

11 MRC, (2010). State of the Basin Report 2010. Mekong River Commission. 12 http://www.mrcmekong.org/assets/Publications/basin-reports/MRC-SOB-report-2010full-

13 report.pdf

14

15

MRC, (2011). THE FLOOD MANAGEMENT AND MITIGATION PROGRAMME 2011162015.

Mekong

River

Commission.

17 http://www.mrcmekong.org/assets/Publications/Programme-Documents/FMMP-2011-2015-

18 Programme-Document-Volume-1-file-date-21042011.pdf

19

20 MRC, (2012). Work Programme 2012. Mekong River Commission.

21 http://www.mrcmekong.org/assets/Publications/strategies-workprog/work-program-12-

22 final.pdf

23

24 MRC, (2010). Strategic Environmental Assessment of Hydropower on Mekong Mainstream. 25 Mekong River Commission.

26 http://www.mrcmekong.org/assets/Publications/Consultations/SEA-Hydropower/SEA-Main-

27 Final-Report.pdf 
1 MRC, (2012). The Impact \& Management of Floods \& Droughts in the Lower Mekong Basin

$2 \&$ the Implications of Possible Climate Change. Mekong River Commission.

3 http://www.mrcmekong.org/assets/Publications/basin-reports/FMMP-working-paper-

$4 \quad$ 110820.pdf

5

6 MRC, (2015). Annual Mekong Flood Report 2011. Mekong River Commission.

7 http://www.mrcmekong.org/assets/Publications/basin-reports/Annual-Mekong-Flood-Report-

$8 \quad$ 2011.pdf

9

Nigro, J., Slayback, D., Policelli, F., \& Brakenridge, G. R. (2014). NASA/DFO MODIS Near Real-Time (NRT) Global Flood Mapping Product Evaluation of Flood and Permanent Water Detection. (3)

Notre Dame Global Adaptation Index (ND-GAIN) (2015). Notre Dame Global Adaptation Institute. Accessed 1 September 2015. http://index.gain.org/.

Pekel, J. F., Vancutsem, C., Bastin, L., Clerici, M., Vanbogaert, E., Bartholomé, E., \& Defourny, P. (2014). A near real-time water surface detection method based on HSV transformation of MODIS multi-spectral time series data. Remote sensing of environment, $140,704-716$.

Räsänen, T. A., Someth, P., Lauri, H., Koponen, J., Sarkkula, J., \& Kummu, M. (2017). Observed river discharge changes due to hydropower operations in the Upper Mekong Basin. Journal of Hydrology, 545, 28-41.

Raza, S. F., Ahsan, M. S., \& Ahmad, S. R. (2015). Rapid assessment of a flood-affected population through a spatial data model. Journal of Flood Risk Management. 
1 Sanyal, J., Lu, X. X. (2004). Application of remote sensing in flood management with special

2 reference to monsoon Asia: a review. Natural Hazards, 33(2), 283-301.

3

4 Schiermeier, Q. (2011). Increased flood risk linked to global warming. Nature, 470(7334), $5 \quad 316-316$.

6

7 Standard and Poor's, (2014). Climate Change Is A Global Mega-Trend For Sovereign Risk.

8 https://www.globalcreditportal.com/ratingsdirect/renderArticle.do?articleId=1318252\&SctArt

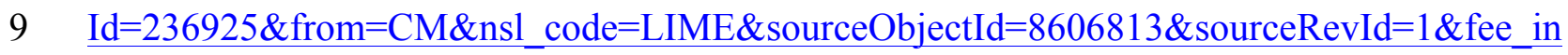

10 d=N\&exp_date=20240514-20:34:43. Last Accessed April 30, 2016.

11

12 Stromberg, D. (2007). Natural Disasters, Economic Development, and Humanitarian Aid. The 13 Journal of Economic Perspectives. 21(3):199-222.

14

15 Van Zalinge, N., Degen, P., Pongsri, S., Nuov, S., Jensen., J.G., Nguyen, V.H., Choulamany, 16 X. (2004). The Mekong River System. In: Proceedings of the Second International 17 Symposium on the Management of Large Rivers for Fisheries Volume I. Welcomme R. and 18 T. Petr, Eds., FAO Regional Office for Asia and the Pacific, Bangkok, Thailand. RAP 19 Publication 2004/16, pp. 1-20.

21 Tucker, C.J. (1979). Red and Photographic Infrared Linear Combinations for Monitoring 22 Vegetation, Remote Sensing of Environment, 8(2),127-150.

23

24 USDA, (2013). Cambodia: Seasonal Flooding Impacts Wet Season Rice Production in 2013. 25 United States Department of Agriculture. 26 http://www.pecad.fas.usda.gov/highlights/2013/11/Cambodia/. Last accessed April 30, 2016. 
1 Västilä, K., Kummu, M., Sangmanee, C., \& Chinvanno, S. (2010). Modelling climate change

2 impacts on the flood pulse in the Lower Mekong floodplains. Journal of Water and Climate

3 Change, 1(1), 67-86.

4

5 E. Vermote. (2016). MOD09A1 MODIS/Terra Surface Reflectance 8-Day L3 Global 500m 6 SIN Grid V006. NASA EOSDIS Land Processes DAAC. Retrieved from 7 https://doi.org/10.5067/MODIS/MOD09A1.006

8

9 Voisin, N., Wood, A. W., \& Lettenmaier, D. P. (2008). Evaluation of precipitation products

10 for global hydrological prediction. Journal of Hydrometeorology, 9(3), 388-407.

11

12 Westerhoff, R.S.; Kleuskens, M.P.H.; Winsemius, H.C.; Huizinga, H.J.; Brakenridge, G.R.;

13 Bishop, C. (2013) Automated global water mapping based on wide-swath orbital synthetic14 aperture radar. Hydrol. Earth Syst. Sci. 17, 651-663.

15

16 Wu, H., Adler, R. F., Tian, Y., Huffman, G. J., Li, H., \& Wang, J. (2014). Real-time global 17 flood estimation using satellite-based precipitation and a coupled land surface and routing model. Water Resources Research, 50(3), 2693-2717.

19

20 Xiao, X., Boles, S., Frolking, S., Li, C., Babu, J. Y., Salas, W., \& Moore, B. (2006). Mapping 21 paddy rice agriculture in South and Southeast Asia using multi-temporal MODIS 22 images. Remote Sensing of Environment, 100(1), 95-113. 